\title{
Activation of PPAR $\gamma$ and $\delta$ by dietary punicic acid ameliorates intestinal inflammation in mice
}

\author{
Josep Bassaganya-Riera ${ }^{1 *}$, Margaret DiGuardo ${ }^{2}$, Montse Climent $^{1}$, Cristina Vives ${ }^{1}$, Adria Carbo ${ }^{1}$, \\ Zeina E. Jouni ${ }^{3}$, Alexandra W. C. Einerhand ${ }^{4}$, Marianne O'Shea $^{4}$ and Raquel Hontecillas ${ }^{1}$ \\ ${ }^{1}$ Laboratory of Nutritional Immunology and Molecular Nutrition, Virginia Bioinformatics Institute, Virginia Polytechnic \\ Institute and State University, Blacksburg, VA 24061, USA \\ ${ }^{2}$ Nutrition Therapeutics, Inc., Blacksburg, VA 24061, USA \\ ${ }^{3}$ Mead Johnson Nutrition, Evansville, IN 47721, USA \\ ${ }^{4}$ Lipid Nutrition BV, Channahon, IL 60410, USA
}

(Received 11 May 2010 - Revised 13 January 2011 - Accepted 18 January 2011 - First published online 31 May 2011)

\section{Abstract}

The goal of the present study was to elucidate the mechanisms of immunoregulation by which dietary punicic acid (PUA) prevents or ameliorates experimental inflammatory bowel disease (IBD). The expression of PPAR $\gamma$ and $\delta$, their responsive genes and pro-inflammatory cytokines was assayed in the colonic mucosa. Immune cell-specific PPAR $\gamma$ null, PPAR $\delta$ knockout and wild-type mice were treated with PUA and challenged with $2.5 \%$ dextran sodium sulphate (DSS). The prophylactic efficacy of PUA was examined in an IL-10 ${ }^{-/-}$model of IBD. The effect of PUA on the regulatory T-cell (Treg) compartment was also examined in mice with experimental IBD. PUA ameliorated spontaneous pan-enteritis in IL-10 ${ }^{-/-}$mice and DSS colitis, up-regulated Foxp3 expression in Treg and suppressed TNF- $\alpha$, but the loss of functional PPAR $\gamma$ or $\delta$ impaired these anti-inflammatory effects. At the cellular level, the macrophage-specific deletion of PPAR $\gamma$ caused a complete abrogation of the protective effect of PUA, whereas the deletion of PPAR $\delta$ or intestinal epithelial cell-specific PPAR $\gamma$ decreased its anti-inflammatory efficacy. We provide in vivo molecular evidence demonstrating that PUA ameliorates experimental IBD by regulating macrophage and T-cell function through PPAR $\gamma$ - and $\delta$-dependent mechanisms.

Key words: Inflammatory bowel disease: PPAR: Punicic acid

Inflammatory bowel disease (IBD) is a widespread and debilitating illness characterised by the destruction of the gut mucosa by the mucosal immune system $^{(1)}$. Activation of PPAR $\gamma$ has shown efficacy in the prevention or amelioration of experimental $\mathrm{IBD}^{(2-4)}$. Results of a recent clinical study in ulcerative colitis patients demonstrate that rosiglitazone (Avandia $^{\mathrm{TM}}$; GlaxoSmithKline, London, UK), an agonist of PPAR $\gamma$ and a Food and Drug Administration-approved drug for treating type 2 diabetes, is also efficacious in the treatment of mild-to-moderately active ulcerative colitis ${ }^{(5)}$. In spite of its efficacy, rosiglitazone is unlikely to be adopted for treating IBD due to its significant side effects ${ }^{(6,7)}$ and a Food and Drug Administration-issued 'black box' warning and subsequent restriction of its use. Thus, there is a need to discover novel dual or pan-agonists of PPAR that exert therapeutic and prophylactic actions against IBD with limited or no adverse side effects.
A safer alternative to rosiglitazone in particular, or the thiazolidinedione class of anti-diabetic drugs in general (i.e. rosiglitazone, ciglitazone, troglitazone and pioglitazone), is conjugated linoleic acid (CLA), a naturally occurring fatty acid that ameliorates IBD through a PPAR $\gamma$-dependent mechanism $^{(3,8,9)}$. The efficacy of CLA against experimental IBD heightened our interest in discovering naturally occurring, orally active agonists of PPAR. In this regard, conjugated linolenic acids such as punicic acid (PUA), catalpic acid and eleostearic acid have demonstrated some promising effects as dual or pan-agonists of $\operatorname{PPAR}^{(3,10,11)}$. PUA is naturally found at high concentrations in the seed of Punica granatum (Punicaceae, pomegranate) ${ }^{(12)}$ amounting to $64-83 \%$ of the pomegranate seed fatty acids ${ }^{(13,14)}$. Structurally, PUA is a conjugated octadecatrienoic acid containing $c 9, t 11, c 13$ double bonds, resembling the $c$ 9, $t$ 11-CLA isomer - the predominant isomer in milk and beef ${ }^{(15,16)}$.

Abbreviations: cDNA, complementary DNA; CLA, conjugated linoleic acid; DK, double knockout; DSS, dextran sodium sulphate; IBD, inflammatory bowel disease; IEC, intestinal epithelial cell; PUA, punicic acid.

*Corresponding author: Dr J. Bassaganya-Riera, fax +1 540231 2606, email jbassaga@vt.edu 
by blinded observers. Disease activity indices were calculated using a modification of a previously published compounded clinical score ${ }^{(3,32)}$. Briefly, disease activity index consisted of a scoring for diarrhoea and lethargy (0-3), whereas rectal bleeding consisted of a visual observation of blood in faeces and the perianal area $(0-4)$. Results from preliminary studies demonstrated a high correlation between the results of faecal blood by Hemoccult and visual observations performed by experienced veterinarians. Mice in the DSS study were euthanised by $\mathrm{CO}_{2}$ narcosis followed by secondary thoracotomy on day 7 of the DSS challenge.

\section{Histopathology}

Segments of the colon $(3 \mathrm{~cm}$ of the anatomic middle of the colon) were fixed in $10 \%$ buffered neutral formalin, later embedded in paraffin, and then sectioned $(6 \mu \mathrm{m})$ and stained with haematoxylin and eosin for histological examination. Tissue slides were examined as described previously ${ }^{(3,33,34)}$. Briefly, colons were graded with a compounded histological score including the extent of (1) crypt damage, (2) regeneration, (3) metaplasia/hyperplasia, (4) lamina proprial vascular changes, (5) submucosal changes and (6) presence of inflammatory infiltrates. The sections were graded with a range from 0 to 4 for each of the previous categories, and data were
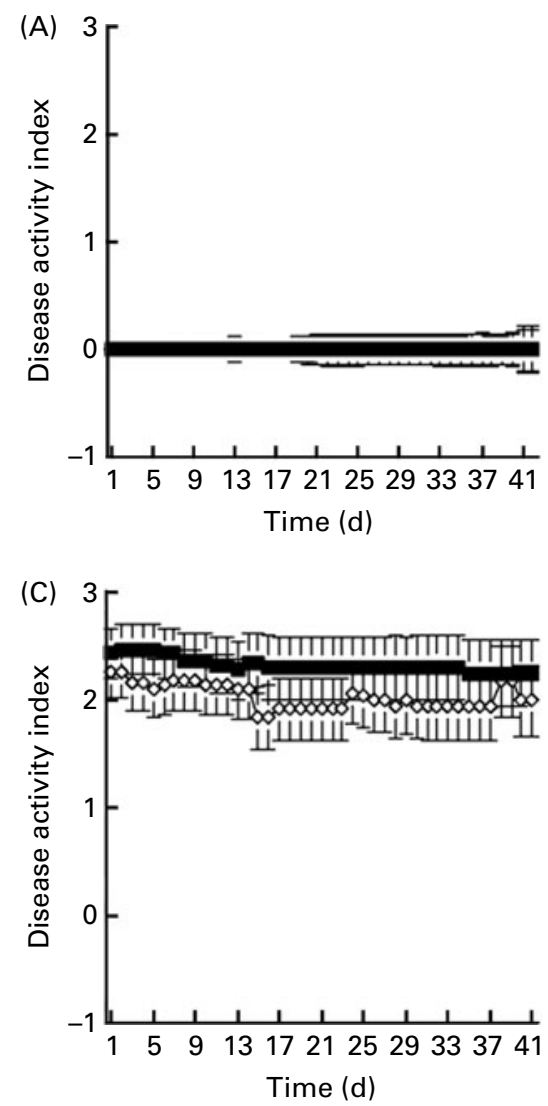

analysed as a normalised compounded score. We show the colonic results because the colonic lesions are common in the $\mathrm{IL}-10^{-1-}$ and DSS colitis models. The ileal lesions can only be found in the IL- $10^{-/-}$model but not in the DSS model, which is colon-specific.

\section{Quantitative real-time RT-PCR from the colon}

Total RNA was isolated from colonic samples using the RNeasy isolation kit (Qiagen, Valencia, CA, USA) to examine the expression of the three PPAR isoforms and PPAR-responsive genes. The PCR primer pairs for the genes of interest were designed based on previously published sequences (GenBank) using the Oligo 6 primer design software (Molecular Biology Insights, Cascade, CO, USA), and real-time RT-PCR was performed as described previously ${ }^{(3,9)}$. Briefly, total RNA was isolated from the whole colon of mice using the RNA isolation MiniKit (Qiagen) according to the manufacturer's instructions. All RNA samples were checked for quality and quantity on the Agilent 2100 BioAnalyser system (Agilent Technologies, Palo Alto, CA, USA). Total RNA ( $1 \mu \mathrm{g})$ from each sample was used to generate a complementary DNA (cDNA) template using the iScript cDNA Synthesis Kit (Bio-Rad, Hercules, CA, USA). The total reaction volume was $20 \mu$ l. The reaction was incubated in a Tetrad thermocycler
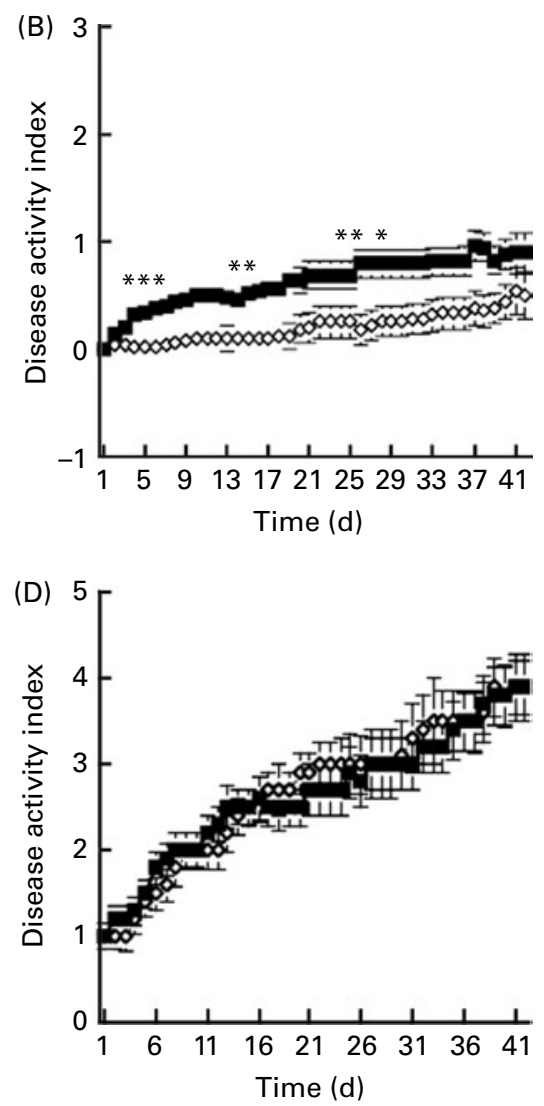

Fig. 1. Effect of punicic acid (PUA) on disease activity indices during $42 \mathrm{~d}$. (A) C57BL/6J wild-type mice fed either a control (- - -) diet or a diet supplemented

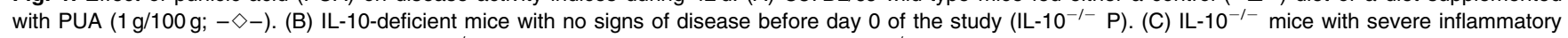
bowel disease on day 0 of the study $\left(\mathrm{IL}-10^{-/-} \mathrm{T}\right)$. (D) PPAR $\gamma \mathrm{fl} / \mathrm{fl}$; MMTV-Cre+; IL-10 ${ }^{-/-}$double knockout mice. ${ }^{*} \mathrm{Mean}$ values were significantly different between the treatments $(P<0.05, n 10)$. 
(MJ Research, Waltham, MA, USA) as follows: $5 \mathrm{~min}$ at $25^{\circ} \mathrm{C}$, $30 \mathrm{~min}$ at $42^{\circ} \mathrm{C}, 5 \mathrm{~min}$ at $85^{\circ} \mathrm{C}$, hold at $4^{\circ} \mathrm{C}$. cDNA products were diluted $1: 10$ in diethylpyrocarbonate-treated water. Controls were also performed with no RNA template (no template) and omitting the RT enzyme (no RT).

The PCR primer pairs were designed based on previously published sequences (GenBank) using the Oligo 6 primer design software (Molecular Biology Insights). The PCR primer pair sequences, annealing temperatures, accession numbers and PCR product lengths are outlined in Table S1 of the supplementary material (available online at http:// www.journals.cambridge.org/bjn.org). PCR was performed on cDNA using Taq DNA Polymerase obtained from Invitrogen (Carlsbad, CA, USA) and using previously described conditions $^{(8,35)}$, and each gene amplicon was purified using the MinElute PCR Purification kit (Qiagen). The purified amplicon for each gene was quantified on an agarose gel and also with the GeneQuant Pro spectrophotometer (Amersham Biosciences, Piscataway, NJ, USA). These purified amplicons were further used to optimise the real-time PCR conditions and to generate the standard curves in the real-time PCR assay. Primer concentrations and annealing temperatures were optimised for the iCycler iQ System (Bio-Rad) for each set of primers using the system's gradient protocol. PCR efficiencies were maintained at $100 \%$ for each primer set during optimisation and also during the real-time PCR of sample cDNA.

\section{Statistical analyses}

ANOVA was used to determine the statistical significance of the model: main effects of diet, genotype, time, two-way and three-way interactions when time was a factor. ANOVA was performed using the general linear model procedure of Statistical Analysis Software (SAS Institute, Inc., Cary, NC, USA) as described previously ${ }^{(36)}$. Data were analysed as factorial arrangements of treatments. The statistical model was $Y_{i j k}=\mu+$ genotype $_{i}+\operatorname{diet}_{j}+(\text { genotype } \times \operatorname{diet})_{i j}+\operatorname{error} A_{i j k}$,

where $\mu$ is the general mean, genotype ${ }_{i}$ is the main effect of the $i$ th level of the genotypic effect (expression of PPAR $y$ by the immune and epithelial cells), diet ${ }_{j}$ is the main effect of the $j$ th level of the dietary effect (PUA $v$. control), (genotype $\times$ diet $_{i j}$ is the interaction effect between genotype and diet, and error $A$ is the random error. When the model was significant, the analysis was followed by Scheffe's multiple comparison method. Data are expressed as means with their standard errors of the mean. For analysing the results of the disease activity index over time, we used a threefactor repeated-measures ANOVA. For this analysis, in addition to the main effects of diet and genotype and the two-way interaction between diet and genotype (as shown earlier), the model included the main effect of time, the diet $\times$ time, genotype $x$ time interactions and the three-factor interaction (diet $\times$ genotype $\times$ time). Statistical significance was assessed at a probability value $(P<0 \cdot 05)$.

\section{Results}

\section{Disease activity indices}

No effect of PUA was observed in disease activity indices of wild-type mice (Fig. 1(A)). PUA prevented experimental IBD in IL- $10^{-1-}$ mice (Fig. 1(B)). Even though there were some favourable numerical differences, PUA did not cure IBD in mice that received it after having developed severe clinical signs such as rectal prolapses (Fig. 1(C)). The deficiency of PPAR $\gamma$ in immune and epithelial cells in PPAR $\gamma$ fl/fl; MMTVCre+ ; IL-10 DK mice abrogated the beneficial effect of PUA in experimental IBD (Fig. 1(D)) even when PUA was administered preventively. Even though we also attempted to generate a line of PPARS; IL-10 DK, we were unable to produce this line due to embryonic mortality associated with this genotype. Thus, we evaluated the role of PPAR $\delta$ in PUA-mediated protection from IBD using a model of DSS colitis.

\section{Intestinal inflammatory lesions}

The architecture of colons recovered from $\mathrm{IL}-10^{-/-} \mathrm{P}$ mice administered PUA resembled those of healthy wild-type mice. Specifically, PUA significantly decreased the histological scores, including lymphoplasmacytic infiltration and enlargement of
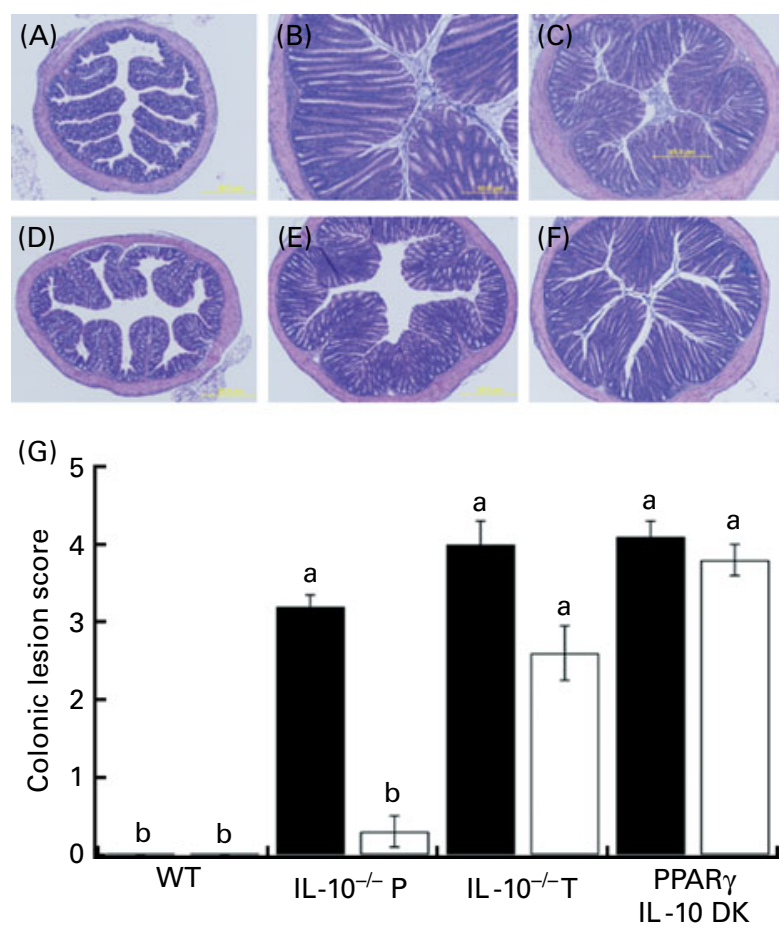

Fig. 2. Effect of punicic acid (PUA) on microscopic lesions observed following $42 \mathrm{~d}$ of dietary supplementation. Representative photomicrographs of colons of (A and D) wild-type, (WT; $B$ and $E$ ) $\mathrm{IL}-10^{-1-} \mathrm{P}$ and (C and $\mathrm{F}$ ) $\mathrm{IL}-10^{-1-} \mathrm{T}$ mice fed a control diet $(\mathrm{A}-\mathrm{C})$ or a PUA-supplemented diet $(\mathrm{D}-\mathrm{F})$ for $42 \mathrm{~d}$. The intestinal specimens were excised, stored in formalin, sectioned and stained with haematoxylin and eosin. Original magnification at $40 \times$. (G) Wild-type, IL-10 $0^{-1-} \mathrm{P}$ and $\mathrm{IL}-10^{-1-} \mathrm{T}$ and PPAR $\gamma \mathrm{fl} / \mathrm{fl}$; MMTV-Cre + ; $\mathrm{IL}-10^{-1-}$ double knockout mice were fed either a control diet ( $\square$ ) or a PUAsupplemented diet $(\square)$ for $42 \mathrm{~d}$. Colonic histological lesions were scored by blinded observers based on size and morphology (0-4) as described in the Materials and Methods section. ${ }^{a, b}$ Mean values with unlike letters were significantly different $(P<0.05, n 10)$. 
the colonic mucosa of $\mathrm{IL}-10^{-/-} \mathrm{P}$, but not in $\mathrm{IL}-10^{-/-} \mathrm{T}$, mice or in PPAR $\gamma$ fl/fl; MMTV-Cre+ ; IL-10 DK mice (Fig. 2).

\section{Quantification of colonic gene expression}

Quantitative real-time RT-PCR analyses demonstrated that colonic PPAR $\delta$ was significantly up-regulated, and the expression of PPAR $\delta$-responsive gene angiopoietin-like 4 was numerically increased by PUA (Fig. 3(A) and (B)). No differences were observed in the colonic expression of PPAR $\alpha, \gamma$ or their responsive genes CD36, FABP 4 and stearoyl coenzyme A desaturase 1 (data not shown). PUA suppressed the colonic expression of both TNF- $\alpha$ and MCP-1 (Fig. 3(C) and (D)). PUA significantly up-regulated the colonic expression of keratinocyte growth factor in comparison with control diet-fed mice (0.01 v. 0.005, P<0.02). Kerationocyte growth factor is a growth factor associated with epithelial wound healing.

Effect of cell-specific deficiency of PPAR $\gamma$ and $\delta$ on the ability of punicic acid to prevent or ameliorate dextran sodium sulphate colitis

PUA protected wild-type mice from experimental IBD, but its beneficial effects in disease activity and colonic lesions were abrogated in PPAR $\delta$ null mice (Fig. 4) and significantly impaired in IEC-specific (Villin-Cre) (Fig. 5) and macrophage-specific (Lysozyme M-Cre) PPAR $\gamma$ null mice (Fig. 6), suggesting that PPAR $\gamma$ and $\delta$ in immune and epithelial cells are required for PUA-mediated protection from experimental IBD. The highest disease activity was observed in Lysozyme M-Cre mice, regardless of the diet (Fig. 6), indicating that the deficiency of PPAR $\gamma$ in macrophages is a particularly important contributor to the immunopathogenesis of IBD, as shown previously ${ }^{(29)}$. Flow cytometric analyses of T-cell subsets in blood and mesenteric lymph nodes (MLN) demonstrated that PUA increased the percentages of regulatory T-cells in the blood of wild-type mice but not in mice lacking PPAR $\gamma$ or $\delta$ in immune or epithelial cells (Fig. 7).

\section{Discussion}

Nutritional influences can target the main components of mucosal homeostasis during IBD and contribute to either attenuating or accentuating the onset of disease ${ }^{(37,38)}$. Both fatty acid composition of the diet and total amount of dietary fat $^{(39-41)}$ define the variables of lipid nutrition that influence health and disease. For instance, mixed results are available on the modulation of intestinal inflammation by $n-3$ PUFA, although CLA has shown anti-inflammatory efficacy more consistently, primarily by targeting $\operatorname{PPAR}^{(42)}$. At the molecular level, PPAR represent important targets for the actions of
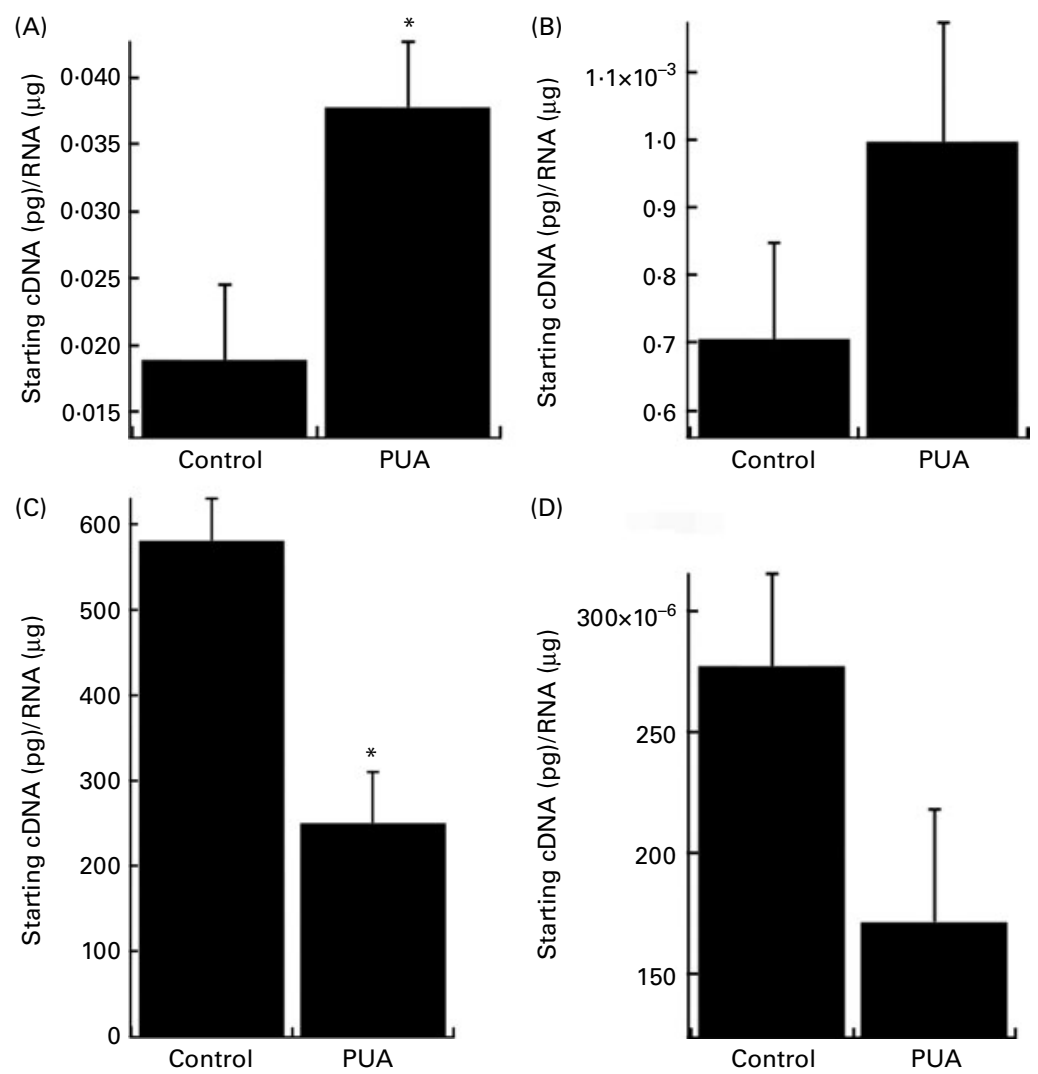

(D)

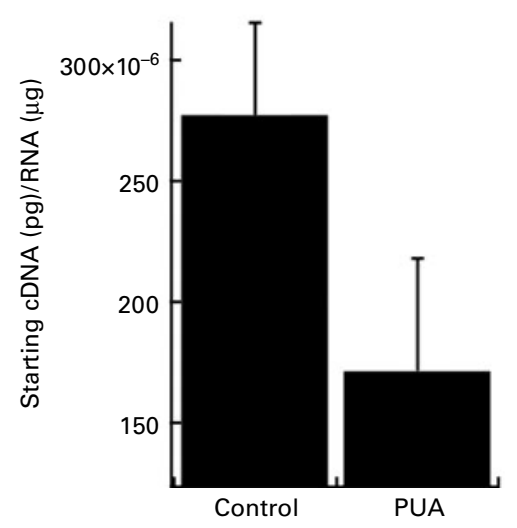

Fig. 3. Quantification of mRNA expression of (A) PPAR $\delta$, (B) angiopoietin-like 4, (C) TNF- $\alpha$ and (D) monocyte chemoattractant protein 1 in colons of IL-10 ${ }^{-/-}$ mice fed a control diet or a punicic acid (PUA)-supplemented $(1 \mathrm{~g} / 100 \mathrm{~g})$ diet using real-time RT-PCR. Colonic samples were collected from IL-10 ${ }^{-1-}$ mice fed PUA preventively. Values are means, with standard errors represented by vertical bars (ten mice per group). ${ }^{*}$ Mean values were significantly different $(P<0.05)$. cDNA, complementary DNA. 


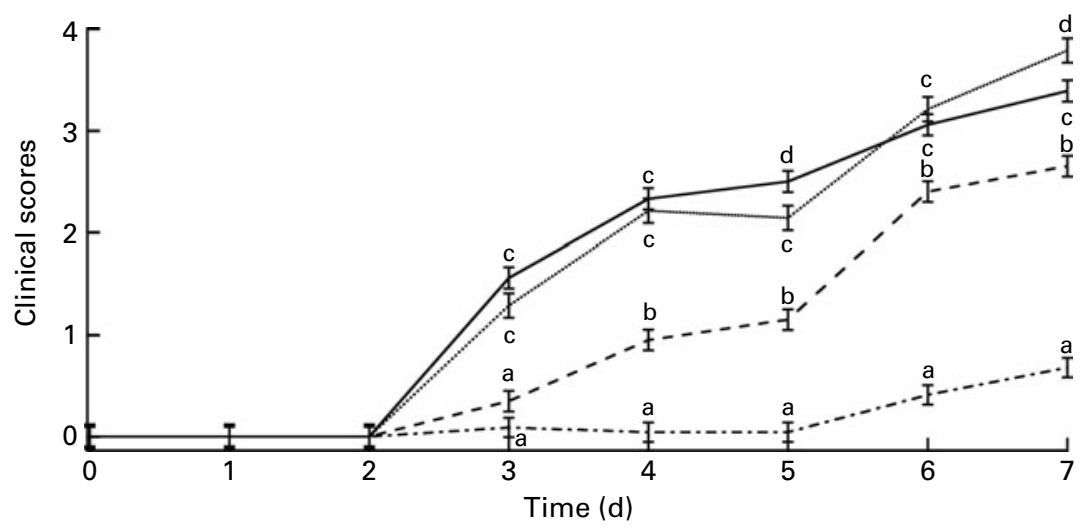

Fig. 4. Effect of dietary punicic acid (PUA) supplementation on experimental inflammatory bowel disease during a $7 \mathrm{~d}$ challenge with dextran sodium sulphate. (A) Disease activity indices, (B) gross lesions in C57BL/6J wild-type (WT) and PPAR $\delta$ null mice fed either a control or a PUA-supplemented diet. Values are means, with standard errors represented by vertical bars. ${ }^{\mathrm{a}, \mathrm{b}, \mathrm{c}, \mathrm{d}}$ Mean values with unlike letters were significantly different $(P<0.05, n 10) .---$, WT control; --- , WT

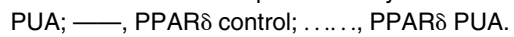

dietary lipid ${ }^{(43)}$ and major contributors to the maintenance of intestinal homeostasis. In this regard, PPAR $\gamma$ gene therapy enhances PPAR $\gamma$ mRNA expression, resulting in dramatic therapeutic benefits in the DSS colitis model ${ }^{(2)}$. CLA induced colonic PPAR $\gamma$ expression and provided protection against the disease in a pig model of bacterial-induced colitis ${ }^{(8)}$, as well as in mouse and pig models of DSS colitis ${ }^{(3,9)}$. The present study investigates the possibility of a PPAR-dependent mechanism underlying the anti-inflammatory efficacy of PUA against experimental IBD.

PPAR $\gamma$ and $\delta$ are recognised as central inhibitors of intestinal inflammation in DSS colitis ${ }^{(44-47)}$. In addition, activation of PPAR $\gamma$ by rosiglitazone ameliorated spontaneous panenteritis caused by the deficiency of $\mathrm{IL}-10^{(4)}$. In the present study, we provide evidence that preventive administration of PUA ameliorated IBD in two mouse models of IBD. However, PUA was not effective in $\mathrm{IL}-10^{-/-}$mice with established severe inflammatory lesions (i.e. rectal prolapses) and PPARy; IL-10 DK mice. The latter finding suggests that the anti-inflammatory efficacy of PUA depends on the expression of functional PPAR $\gamma$ in immune and epithelial cells. Interestingly, colonic expression of PPAR $\delta$ and its responsive gene angiopoietin-like 4 was up-regulated in IL-10 $10^{-1-}$ mice that received PUA preventively. These in vivo findings were in line with increased PPAR $\delta$ reporter activity induced by PUA in vitro in IEC and macrophages. As CLA ${ }^{(9)}$, PUA up-regulated colonic kerationocyte growth factor levels in the present study. Since PPAR $\delta$ plays an important role in re-epithelialisation in mouse epidermis ${ }^{(48)}$, the up-regulated colonic keratinocyte growth factor may be indicative of a PPAR $\delta$-mediated re-epithelialisation of the gut mucosa.

In contrast to PPAR $\delta$ and its responsive genes, colonic levels of PPAR $\gamma, \alpha$ and their responsive genes remained unchanged. Nonetheless, since PUA transactivates PPAR $\gamma$ in 3T3-L1 preadipocytes $^{(11)}$ and given the abrogation of the effect of PUA that we observed in PPAR $\gamma$; IL-10 DK mice, this isoform was also investigated as a putative target for PUA. PPAR $\gamma$ suppresses inflammation by antagonising NF-кB, STAT and AP-1 ${ }^{(49)}$, favouring the nucleocytoplasmic shuttling of the activated p65 subunit of NF- $\mathrm{B}^{(50)}$, and SUMOylation of PPAR $\gamma$ results in a stable repressed state of $N F-\kappa B^{(51)}$. Thus, the down-regulation of TNF- $\alpha$ in colons of PUA-fed mice and

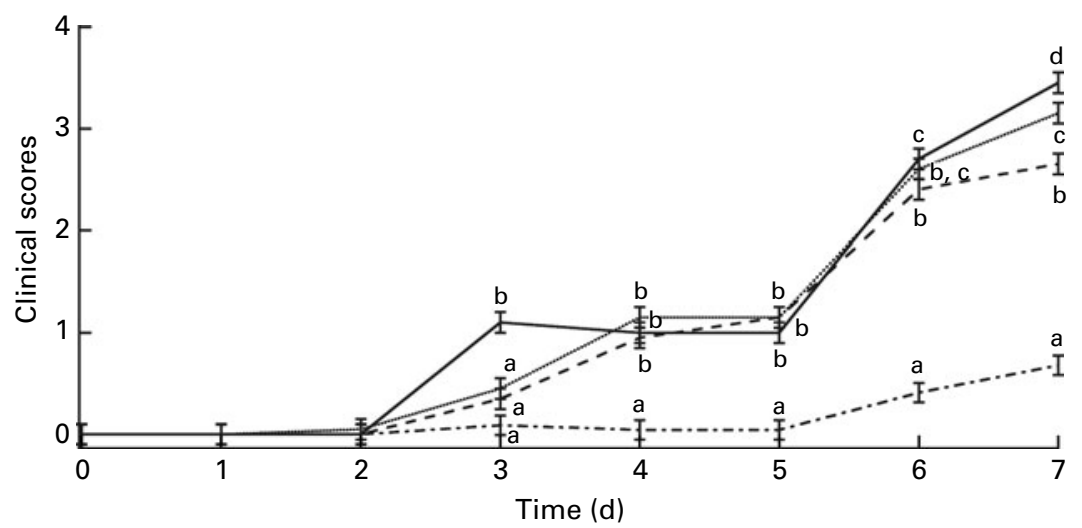

Fig. 5. Effect of dietary punicic acid (PUA) supplementation on experimental inflammatory bowel disease during a $7 \mathrm{~d}$ challenge with dextran sodium sulphate. (A) Disease activity indices, (B) gross lesions in Villin-Cre-C57BL/6J wild-type (WT) and intestinal epithelial cell-specific PPAR $\gamma$ null (Villin-Cre+ ) mice fed either a control diet or a PUA-supplemented diet. Values are means, with standard errors represented by vertical bars. ${ }^{a, b, c, d}$ Mean values with unlike letters were significantly different $(P<0.05, n 10) .---$, WT control; - - - WT PUA; - , VillinCre+ control; ......, VillinCre+ PUA. 


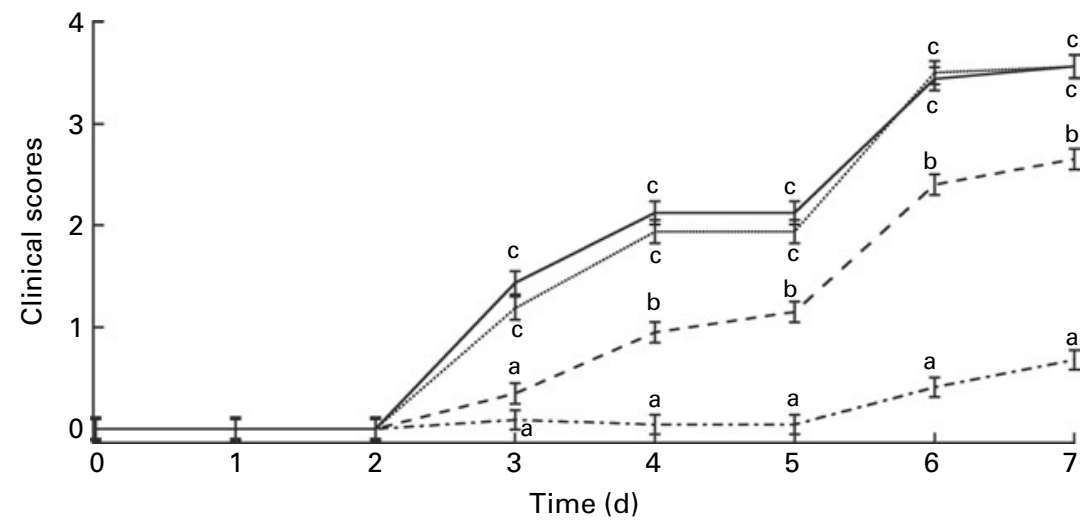

Fig. 6. Effect of dietary punicic acid (PUA) supplementation on experimental inflammatory bowel disease during a $7 \mathrm{~d}$ challenge with dextran sodium sulphate. (A) Disease activity indices, (B) gross lesions in Lysozyme M-Cre-C57BL/6J wild-type (WT) and macrophage-specific PPARy null (Lysozyme M-Cre+ ) mice fed either a control diet or a PUA-supplemented diet. Values are means, with standard errors represented by vertical bars. ${ }^{a, b, c}$ Mean values with unlike letters were significantly different $(P<0.05, n 10)$. - - - WT control; - - -, WT PUA; — - Lysozyme M Cre+ control; ......, Lysozyme M Cre+ PUA.

M1 macrophages treated with PUA is consistent with the PPAR $\gamma$-dependent anti-inflammatory effects of this compound.

The selective PPARy agonist rosiglitazone suppressed colonic inflammation even when PPAR $\gamma$ was deleted from colonic epithelial cells, suggesting either an epithelial PPAR $\gamma$-independent effect or a possible role for macrophages as a cellular target $^{(26)}$. In addition, activation of PPAR $\gamma$ and $\delta$ has been shown to suppress M1 classically activated or pro-inflammatory macrophage activation and favour M2 alternatively activated or anti-inflammatory macrophage differentiation ${ }^{(52-54)}$. Moreover, PPAR $\gamma$ and $\delta$ have been shown to exert overlapping anti-inflammatory effects in lipopolysaccharide-stimulated macrophages ${ }^{(55)}$. Based on this background, to further characterise the putative roles of PPAR $\gamma$ and $\delta$ as targets for PUA, we determined whether the deletion of these genes impaired or abrogated its ability to ameliorate experimental IBD. Our data demonstrate that both PPAR $\gamma$ and $\delta$ are required for PUA-mediated protection from DSS colitis. Additionally, PPAR $\gamma$ was also required for PUA-mediated protection from IL-10-induced pan-enteritis since the preventive effect of PUA was abrogated in PPAR $\gamma$; IL-10 DK mice. However, we could not test the role of PPAR $\delta$ in spontaneous pan-enteritis in IL-10 knockout mice since PPARS; IL-10 DK mice did not survive beyond the embryonic stages.

At the cellular level, the deletion of PPAR $\gamma$ in macrophages completely abrogated the beneficial effect of PUA, whereas its deletion in IEC or the whole-body deletion of PPAR $\delta$ impaired, but did not completely abrogate, the anti-inflammatory activity of PUA in the gut. Together, these data indicate that PUA ameliorates experimental IBD by down-modulating inflammation in mucosal immune and epithelial cells through PPAR $\gamma$ - and $\delta$-dependent mechanisms. In support of this assertion, we provide in vitro evidence demonstrating that PUA treatment suppressed the TNF- $\alpha$ - and MCP-1-producing abilities of wild-type M1 classically activated macrophages, but it failed to exert these suppressive effects in PPAR $\gamma$ or $\delta$ null macrophages. Furthermore, PUA intake increased the peripheral blood regulatory T-cell compartment in wild-type mice but not in PPAR $\gamma$ or $\delta$ null mouse strains. These findings are in line with a PPAR $\gamma$-dependent up-regulation of Foxp3 in regulatory T-cells treated with PUA (data not shown). Of note, regulatory T-cells mediate protection from experimental colitis through PPAR $\gamma$-dependent mechanisms ${ }^{(28,34)}$. Since colonic PPAR $y$ was required for some of the anti-inflammatory effects of PUA in vivo, but it did not activate PPAR $\gamma$ reporter activity

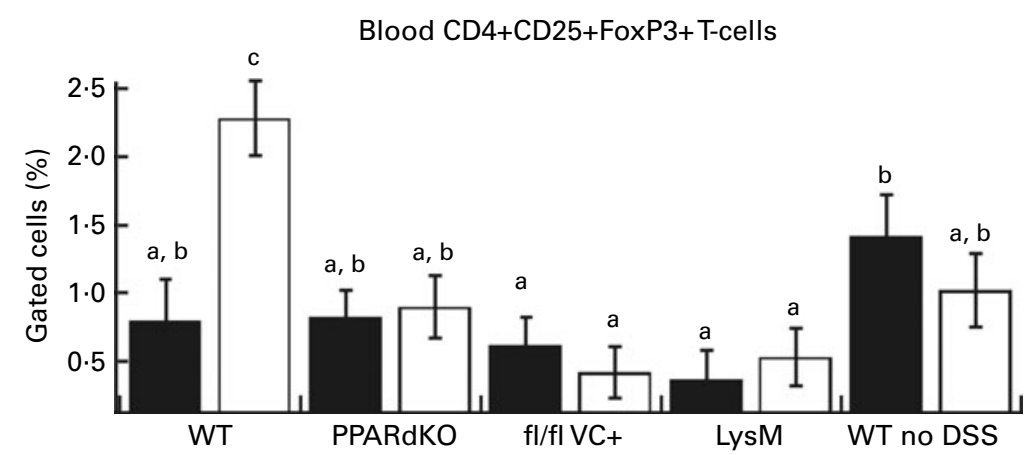

Fig. 7. Dietary punicic acid modulates the percentages of regulatory T-cells in the peripheral blood of C57BL/6J wild-type (WT) mice but not in PPAR null, macrophage-specific PPAR $\gamma$ null (Lysozyme M (LysM)-Cre+), intestinal epithelial cell-specific PPAR $\gamma$ null (Villin-Cre+ (VC+)) mice with dextran sodium sulphate (DSS) colitis. Values are means, with standard errors represented by vertical bars. ${ }^{a, b, c}$ Mean values with unlike letters were significantly different among the treatments $(P<0.05, n 10)$. PPARdKO, PPAR double knockout; WT no DSS, WT without DSS. 
directly, further studies are required to determine whether IEC and/or immune cells produced endogenous PPAR $\gamma$ agonists in response to PUA-mediated activation of PPAR $\delta$. In conclusion, PUA prevented experimental IBD through a mechanism requiring adequate expression of PPAR $\gamma$ and $\delta$ in immune cells and IEC in the colonic mucosa.

\section{Acknowledgements}

The present study was supported by funds from Lipid Nutrition BV. J. B.-R., R. H., Z. E. J., M. O'. S. and A. W. C. E. designed the experiments, interpreted the results, wrote the manuscript and managed the project. M. D., M. C., C. V. and A. C. conducted the animal studies. M. C. and C. V. conducted the in vitro studies. J. B.-R. filed a patent related to PUA. R. H., Z. E. J., M. O'. S., A. W. C. E., M. D., M. C., C. V. and A. C. declare that they have no conflict of interests.

\section{References}

1. Strober W, Fuss IJ \& Blumberg RS (2002) The immunology of mucosal models of inflammation. Annu Rev Immunol 20, 495-549.

2. Katayama K, Wada K, Nakajima A, et al. (2003) A novel PPARgamma gene therapy to control inflammation associated with inflammatory bowel disease in a murine model. Gastroenterology 124, 1315-1324.

3. Bassaganya-Riera J, Reynolds K, Martino-Catt S, et al. (2004) Activation of PPAR gamma and delta by conjugated linoleic acid mediates protection from experimental inflammatory bowel disease. Gastroenterology 127, 777-791.

4. Lytle C, Tod TJ, Vo KT, et al. (2005) The peroxisome proliferator-activated receptor gamma ligand rosiglitazone delays the onset of inflammatory bowel disease in mice with interleukin 10 deficiency. Inflamm Bowel Dis 11, 231-243.

5. Lewis JD, Lichtenstein GR, Deren JJ, et al. (2008) Rosiglitazone for active ulcerative colitis: a randomized placebocontrolled trial. Gastroenterology 134, 688-695.

6. Marcy TR, Britton ML \& Blevins SM (2004) Second-generation thiazolidinediones and hepatotoxicity. Ann Pharmacother 38, 1419-1423.

7. Nesto RW, Bell D, Bonow RO, et al. (2003) Thiazolidinedione use, fluid retention, and congestive heart failure: a consensus statement from the American Heart Association and American Diabetes Association. Circulation 108, 2941-2948.

8. Hontecillas R, Wannemeulher MJ, Zimmerman DR, et al. (2002) Nutritional regulation of porcine bacterial-induced colitis by conjugated linoleic acid. J Nutr 132, 2019-2027.

9. Bassaganya-Riera J \& Hontecillas R (2006) CLA and n-3 PUFA differentially modulate clinical activity and colonic PPARresponsive gene expression in a pig model of experimental IBD. Clin Nutr 25, 454-465.

10. Hontecillas R, Diguardo M, Duran E, et al. (2008) Catalpic acid decreases abdominal fat deposition, improves glucose homeostasis and upregulates PPAR alpha expression in adipose tissue. Clin Nutr 27, 764-772.

11. Hontecillas R, O'Shea M, Einerhand A, et al. (2009) Activation of PPAR gamma and alpha by punicic acid ameliorates glucose tolerance and suppresses obesity-related inflammation. J Am Coll Nutr 28, 184-195.
12. Sassano GP, Sanderson J, Franx P, et al. (2009) Analysis of pomegranate seed oil for the presence of jacaric acid. J Food Sci Agric 6, 1046-1052.

13. Ahlers NHE, Dennison AC \& O'Neill LA (1954) Spectroscopic examination of punicic acid. Nature 173, 1045-1046.

14. Kaufman M \& Wiesman Z (2007) Pomegranate oil analysis with emphasis on MALDI-TOF/MS triacylglycerol fingerprinting. J Agric Food Chem 55, 10405-10413.

15. Bassaganya-Riera J, Hontecillas R \& Beitz DC (2002) Colonic anti-inflammatory mechanisms of conjugated linoleic acid. Clin Nutr 21, 451-459.

16. O'Shea M, Bassaganya-Riera J \& Mohede IC (2004) Immunomodulatory properties of conjugated linoleic acid. Am J Clin Nutr 79, Suppl. 6, 1199S-1206S.

17. McFarlin BK, Strohacker KA \& Kueht ML (2009) Pomegranate seed oil consumption during a period of high-fat feeding reduces weight gain and reduces type 2 diabetes risk in CD-1 mice. Br J Nutr 102, 54-59.

18. Arao K, Wang YM, Inoue N, et al. (2004) Dietary effect of pomegranate seed oil rich in 9 cis, 11trans, 13 cis conjugated linolenic acid on lipid metabolism in obese, hyperlipidemic OLETF rats. Lipids Health Dis $\mathbf{3}, 24$.

19. Meerts IA, Verspeek-Rip CM, Buskens CA, et al. (2009) Toxicological evaluation of pomegranate seed oil. Food Chem Toxicol 47, 1085-1092.

20. Boussetta T, Raad H, Letteron P, et al. (2009) Punicic acid a conjugated linolenic acid inhibits TNFalpha-induced neutrophil hyperactivation and protects from experimental colon inflammation in rats. PLoS One 4 , e6458.

21. Kohno H, Suzuki R, Yasui Y, et al. (2004) Pomegranate seed oil rich in conjugated linolenic acid suppresses chemically induced colon carcinogenesis in rats. Cancer Sci 95, 481-486.

22. Akiyama TE, Sakai S, Lambert G, et al. (2002) Conditional disruption of the peroxisome proliferator-activated receptor gamma gene in mice results in lowered expression of ABCA1, ABCG1, and apoE in macrophages and reduced cholesterol efflux. Mol Cell Biol 22, 2607-2619.

23. Wagner KU, McAllister K, Ward T, et al. (2001) Spatial and temporal expression of the Cre gene under the control of the MMTV-LTR in different lines of transgenic mice. Transgenic Res 10, 545-553.

24. Cui Y, Miyoshi K, Claudio E, et al. (2002) Loss of the peroxisome proliferation-activated receptor gamma (PPARgamma) does not affect mammary development and propensity for tumor formation but leads to reduced fertility. J Biol Chem 277, 17830-17835.

25. Barak Y, Liao D, He W, et al. (2002) Effects of peroxisome proliferator-activated receptor delta on placentation, adiposity, and colorectal cancer. Proc Natl Acad Sci U S A 99, 303-308.

26. Adachi M, Kurotani R, Morimura K, et al. (2006) Peroxisome proliferator activated receptor gamma in colonic epithelial cells protects against experimental inflammatory bowel disease. Gut 55, 1104-1113.

27. Mohapatra SK, Guri AJ, Climent M, et al. (2010) Immunoregulatory actions of epithelial cell PPAR gamma at the colonic mucosa of mice with experimental IBD. PLOS One 5, e10215.

28. Wohlfert EA, Nichols FC, Nevius E, et al. (2007) Peroxisome proliferator-activated receptor gamma (PPARgamma) and immunoregulation: enhancement of regulatory $\mathrm{T}$ cells through PPARgamma-dependent and -independent mechanisms. J Immunol 178, 4129-4135.

29. Shah Y, Morimura K \& Gonzalez F (2006) Expression of peroxisome proliferator-activated receptor-\{gamma in macrophage suppresses experimentally-induced colitis. Am J Physiol Gastrointest Liver Physiol 292, G657-G666. 
30. Hontecillas R, Horne WT, Guri AJ, et al. (2010) Immunoregulatory mechanisms of macrophage PPAR gamma in mice with experimental inflammatory bowel disease. Mucosal Immunol, 4, 304-313.

31. Reeves PG, Nielsen FH \& Fahey GC Jr (1993) AIN-93 purified diets for laboratory rodents: final report of the American Institute of Nutrition ad hoc writing committee on the reformulation of the AIN-76A rodent diet. J Nutr 123, 1939-1951.

32. Saubermann LJ, Beck P, De Jong YP, et al. (2000) Activation of natural killer $\mathrm{T}$ cells by alpha-galactosylceramide in the presence of CD1d provides protection against colitis in mice. Gastroenterology 119, 119-128.

33. Bassaganya-Riera J, Ferrer G, Casagran O, et al. (2009) F4/ 80hiCCR2hi macrophage infiltration into the intra-abdominal fat worsens the severity of experimental IBD in obese mice with DSS colitis. e-SPEN J, 4, 90-97.

34. Hontecillas R \& Bassaganya-Riera J (2007) Peroxisome proliferator-activated receptor gamma is required for regulatory $\mathrm{CD} 4+\mathrm{T}$ cell-mediated protection against colitis. J Immunol 178, 2940-2949.

35. Bassaganya-Riera J, Pogranichniy RM, Jobgen SC, et al (2003) Conjugated linoleic acid ameliorates viral infectivity in a pig model of virally induced immunosuppression. J Nutr 133, 3204-3214.

36. Bassaganya-Riera J, Guri AJ, Noble AM, et al. (2007) Arachidonic acid and docosahexaenoic acid-enriched formulas modulate antigen-specific $\mathrm{T}$ cell responses to influenza virus in neonatal piglets. Am J Clin Nutr 85, 824-836.

37. Cantorna MT, Munsick C, Bemiss C, et al. (2000) 1,25-Dihydroxycholecalciferol prevents and ameliorates symptoms of experimental murine inflammatory bowel disease. $J \mathrm{Nutr}$ 130, 2648-2652.

38. Geerling BJ, Badart-Smook A, Stockbrugger RW, et al. (1998) Comprehensive nutritional status in patients with long-standing Crohn disease currently in remission. Am J Clin Nutr 67, 919-926.

39. Calder PC (1998) Dietary fatty acids and the immune system. Nutr Rev 56, (1 Pt 2), S70-S83.

40. Birt DF, Copenhaver J, Barnett T, et al. (1997) Dietary fat and energy modulation of biochemical events in tumor promotion. Adv Exp Med Biol 400B, 925-929.

41. Liu Y, Duysen E, Yaktine AL, et al. (2001) Dietary energy restriction inhibits ERK but not JNK or p38 activity in the epidermis of SENCAR mice. Carcinogenesis 22, 607-612.

42. Bassaganya-Riera J \& Hontecillas R (2010) Dietary conjugated linoleic acid and $n$-3 polyunsaturated fatty acids in inflammatory bowel disease. Curr Opin Clin Nutr Metab Care 13, 569-573.
43. Jump DB \& Clarke SD (1999) Regulation of gene expression by dietary fat. Annu Rev Nutr 19, 63-90.

44. Su CG, Wen X, Bailey ST, et al. (1999) A novel therapy for colitis utilizing PPAR-gamma ligands to inhibit the epithelial inflammatory response. J Clin Invest 104, 383-389.

45. Desreumaux P, Dubuquoy L, Nutten S, et al. (2001) Attenuation of colon inflammation through activators of the retinoid $\mathrm{X}$ receptor (RXR)/peroxisome proliferator-activated receptor gamma (PPARgamma) heterodimer. A basis for new therapeutic strategies. $J$ Exp Med 193, 827-838.

46. Nakajima A, Wada K, Miki H, et al. (2001) Endogenous PPAR gamma mediates anti-inflammatory activity in murine ischemia-reperfusion injury. Gastroenterology 120, 460-469

47. Nakajima A, Wada K, Katayama K, et al. (2002) Gene expression profile after peroxisome proliferator activator receptor-gamma ligand administration in dextran sodium sulfate mice. J Gastroenterol 37, Suppl. 14, 62-66.

48. Michalik L, Desvergne B, Tan NS, et al. (2001) Impaired skin wound healing in peroxisome proliferator-activated receptor (PPAR)alpha and PPARbeta mutant mice. J Cell Biol 154, 799-814.

49. Ricote M, Li AC, Willson TM, et al. (1998) The peroxisome proliferator-activated receptor-gamma is a negative regulator of macrophage activation. Nature 391, 79-82.

50. Kelly D, Campbell JI, King TP, et al. (2004) Commensal anaerobic gut bacteria attenuate inflammation by regulating nuclear-cytoplasmic shuttling of PPAR-gamma and RelA. Nat Immunol 5, 104-112.

51. Pascual G, Fong AL, Ogawa S, et al. (2005) A SUMOylationdependent pathway mediates transrepression of inflammatory response genes by PPAR-gamma. Nature 437, 759-763.

52. Kang K, Reilly SM, Karabacak V, et al. (2008) Adipocytederived Th2 cytokines and myeloid PPARdelta regulate macrophage polarization and insulin sensitivity. Cell Metab 7, 485-495

53. Odegaard JI, Ricardo-Gonzalez RR, Goforth MH, et al. (2007) Macrophage-specific PPARgamma controls alternative activation and improves insulin resistance. Nature $\mathbf{4 4 7}$, $1116-1120$.

54. Odegaard JI, Ricardo-Gonzalez RR, Red Eagle A, et al. (2008) Alternative M2 activation of Kupffer cells by PPARdelta ameliorates obesity-induced insulin resistance. Cell Metab 7, 496-507.

55. Welch JS, Ricote M, Akiyama TE, et al. (2003) PPARgamma and PPARdelta negatively regulate specific subsets of lipopolysaccharide and IFN-gamma target genes in macrophages. Proc Natl Acad Sci US A 100, 6712-6717. 